\title{
Fibrin D-dimer, Markers of Coagulation Activation and the Risk of Major Ischaemic Heart Disease in the Caemphilly Study
}

\author{
Gordon D. O. Lowe ${ }^{1}$, Ann Rumley¹, Peter M. Sweetnam², J ohn W. G. Yarnell³, \\ J oseph Rumley ${ }^{1}$
}

${ }^{1}$ University Department of Medic ine, Royal Infimary, Glasgow, the ${ }^{2}$ MRC Ep idemiology Unit (South Wales), Landough Hospital, Pena rth, and ${ }^{3}$ Division of Epidemiology, Q ueen's University, Belfa st, UK

\section{Keywords}

Fibrin D-dimer, activation markers, ischaemic heart disease

\begin{abstract}
Summany
We have previously reported that plasma fibrin D-dimer (a marker of turnover of cross-linked fibrin) showed a strong and independent association with incident ischaemic heart disease (IHD) in the Caerphilly Study cohort of 1,998 men aged 49-65. To establish the specificity of this finding, we assayed plasma samples from this cohort with a more specific assay for fibrin D-dimer: this showed an association with incident IHD which was at least as strong and independent as that for the original assay (odds ratio, OR for top fifth compared to bottom fifth 3.79; 95\% CI 1.77-8.10; $\mathrm{p}<0.0001$ ). To establish potential causes of the increased fibrin turnover, we also assayed several potential markers of coagulation activation or thrombotic tendency (prothrombin fragment F1+2, thrombin-antithrombin complexes, factor VIIc, activated partial thromboplastin time [APTT] and activated protein $\mathrm{C}$ resistance): none of these variables were associated with incident IHD in this cohort. We suggest that further studies are required to establish the causes of increased cross-linked fibrin turnover, which is associated with incident IHD in the general population when measured by a specific assay.
\end{abstract}

\section{Introduction}

We have recently reported that plasma fibrin D-dimer, a marker of the formation and lysis of cross-linked fibrin $(1,2)$, showed a strong and independent association with incident ischaemic heart disease (IHD) in the Caerphilly Study (3). This finding, which is consistent with results from several other studies (4), was not explained by associations of IHD with plasma fibrinogen (the precursor of fibrin), nor with plasma levels of tissue plasminogen activator (t-PA) antigen or plasminogen activator inhibitor (PAI) activity, which play key roles in

Correspondence to: Prof. G. D. O. Lowe, University Department of Medicine, Glasgow Royal Infirmary, 10 Alexandra Parade, Glasgow, G31 2ER; UK - Tel: +44 141211 5412; Fax: +44 141211 0414; E-mail: gdl1j@clinmed.gla.ac.uk the lysis of fibrin (3). We suggested that increased plasma D-dimer levels in men at increased risk of IHD might reflect increased activation of blood coagulation, because similar elevations of coagulation activation markers and D-dimer have been observed in case-control studies of patients with chronic arterial disease (4-6), and because increased plasma D-dimer levels can be normalised by anticoagulation with warfarin to conventional target INR levels $(7,8)$.

We have performed further investigations in stored, unthawed, deepfrozen plasma samples from this study cohort, to investigate possible causes of the association of fibrin D-dimer with incident IHD. First, we addressed the problem of heterogeneity of D-dimer assays (9) by investigating whether or not the association of D-dimer with incident IHD could be confirmed using a more specific assay which employs a more specific signal antibody (10). Second, we studied the association of several assays of coagulation activation or thrombotic tendency with incident IHD and with D-dimer levels: prothrombin fragment F1+2 and thrombin-antithrombin complexes $(11,12)$, factor VIIc $(13)$, activated partial thromboplastin time (APTT), and activated protein C (APC) resistance using a modification of the original assay of Dählback et al. (14) which we have previously associated with increased levels of coagulation activation markers in another population study (15). We are unaware of reported studies of the correlations between D-dimer and markers of activated coagulation in large samples of the general population.

\section{Subjects and Methods}

The general design and methods of the Caerphilly Study have been described elsewhere (3). Briefly, at each examination the men were invited to attend an afternoon or evening clinic where a detailed medical and lifestyle history was obtained, the London School of Hygiene and Tropical Medicine (LSHTM) chest pain questionnaire was administered, a full 12 lead electrocardiogram (ECG) was recorded, and weight and blood pressure measured. The men were then invited to return, fasting, to an early morning clinic where a blood sample was taken.

\section{Study Population}

The original cohort of 2,512 men aged 45 to 59 years was recruited between 1979 and 1983, and since then they have been re-examined at five yearly intervals. The men who are the subject of this report are those seen at the first re-examination between 1984 and 1988, when they were aged 49 to 65 years. Men of the same age who had moved into the defined geographical area since the original recruitment were also eligible to be examined. A total of 2,398 men attended the evening clinic and a fasting blood sample was obtained from 2,223 (93\%). 


\section{Blood Collection, Storage and Analysis}

Blood was taken between 7.00 am and 10.00 am for $91 \%$ of the men. It was taken before 7.00 am for 7\% and between 10.00 am and 11.00 am for the remaining $2 \%$. The blood was collected without venous stasis into evacuated containers using a 19-gauge butterfly needle and Sarstedt monovette adaptors. Centrifugation was carried out within one hour. The samples used in this study were citrated plasma stored at $-70^{\circ} \mathrm{C}$.

One batch of samples was unavailable for the current analysis, so assays of fibrin D-dimer were performed on 1,998 fasting samples. For comparison with the D-dimer ELISA originally used (Dimertest ELISA, AGEN, Parsippany, New Jersey, USA), D-dimer was re-assayed on 1947 samples using the more specific assay (10) (AGEN Gold, AGEN, Parsippany, New Jersey, USA). The other assays were measured on a separate plasma sample, about one-third of which had previously been used for another purpose. Hence, 1,412 samples were available for assay of Factor VIIc (automated one-stage assay, ACL 300 Research coagulometer, Instrumentation Laboratory, Warrington, UK) using the manufacturer's reagents and British Standard (NIBSC, South Mimms, Herts, UK). In the majority of these samples $(n=1325-1360)$ sufficient residual plasma was available for assays of APTT and APC ratio (ACL 300 Research coagulometer) using Coatest APC-resistance kits (Chromogenix, Stockholm, Sweden) based on the original assay of Dahlbäck et al. $(14,15)$; and prothrombin fragment F1+2 and thrombin-antithrombin (TAT) complexes (ELISA's, Behringwerke, Marburg, Germany) using an automated microtitre plate reader (Dynatec, Billingshurst, UK). The characteristics of this subsample were very similar to those of the whole sample. Fibrinogen (Clauss assay) and factor VIIIc were also assayed in this subsample: their associations with IHD (as well as those for von Willebrand factor antigen and activity) in this cohort are reported elsewhere $(16,17)$.

\section{Incident IHD}

Follow-up was at an average interval of 61 months. All men were flagged with the National Health Service Central Registry and we used death certificates coded to ICD 410-414 inclusive as our definition of fatal IHD. We added to the LSHTM questionnaire some questions about admission to hospital with chest pain. These, together with lists from Hospital Activity Analysis of all men admitted to local hospitals with a diagnosis of ICD 410-414, were used as the basis for a search of hospital notes for events meeting standard World Health Organisation (1996) criteria for acute myocardial infarction (MI). Finally, the appearance on the follow-up electrocardiogram (ECG) of selected major or moderate Q-waves (Minnesota codes 1-1-1 through 1-2-5 and 1-2-7) when there were no Q-waves on the recruitment ECG was taken as evidence that a non-fatal MI had occurred during the follow-up period.

\section{Statistical Methods}

Outlying values of TAT $(\geq 31 \mu \mathrm{g} / \mathrm{L})$ were excluded from statistical analysis (101 out of 1334 measurements excluded). Adjusted mean differences
(Table 4) were obtained by analysis of covariance. All variables except Factor VIIc and APC ratio were transformed to logarithms. The remainder of the analysis was performed using multiple logistic regression analysis with the occurrence, or not, of a major incident IHD event as the dependent variable. The results for the assays were treated in two ways. First, their distributions were divided into equal fifths using the four quintiles, and the results presented as the odds of major incident IHD in each fifth relative to a baseline fifth which was always taken as the $20 \%$ of men with the lowest levels. Second, these variables were entered into the same models as continuous variables to provide a test for the trend in the relative odds of IHD. When treated as continuous variables all, except Factor VIIc and APC ratio, were again transformed to logarithms.

Men with evidence of ischaemia at recruitment were not excluded from the analysis. Reasons for this are given elsewhere (3). Briefly, 31\% of this general population sample men have some evidence of ischaemia at baseline as judged from the LSHTM chest pain questionnaire or the ECG. Exclusion of such a large group, among whom just over half the major incident events occur, does not seem satisfactory. Instead we included standardised measures of angina, history of severe chest pain and ECG ischaemia at baseline as three covariates in the logistic regression analysis. This is likely to be a conservative procedure in that it may underestimate the association between the thrombotic factors and incidence of IHD.

\section{Results}

Table 1 shows the joint distributions of the original D-dimer assay and the more specific D-dimer Gold assay, based on 1,945 samples with fasting values for both assays. There was a strong correlation between the two assays $(r=0.59)$. The fifths of distributions were identical for $35 \%$ of the men, and within \pm 1 fifth for $76 \%$. Only $1.4 \%$ of the men were in the top fifth for one antigen and in the bottom fifth for the other.

Table 2 shows that the values of the D-dimer Gold assay were significantly lower than for the original D-dimer assay. However, both assays showed a strong trend $(\mathrm{p}<0.0001)$ for the incidence of IHD to increase from about $3 \%$ in the $20 \%$ of men with the lowest levels of D-dimer to about $12 \%$ in the $20 \%$ of men with the highest levels. There was no statistically significant difference between the two assays for these associations with incident IHD. As with the original assay (3), controlling for baseline IHD and for conventional risk factors (age, smoking, diastolic blood pressure, body mass index, total and HDL cholesterol, diabetes, family history of MI before age 55, and time of blood sample), reduced the trend for D-dimer Gold, but it remained highly statistically significant ( $<<0.0001$ ); and the relative odds in the top fifth when compared to the bottom fifth were $3.79(95 \% \mathrm{CI}$ 1.77-8.10). The further inclusion of fibrinogen into the model had no effect whatsoever on this association (data not shown).
Table 1 Joint distributions of D-dimer and D-dimer gold

\begin{tabular}{|c|c|c|c|c|c|c|c|}
\hline & & \multicolumn{6}{|c|}{ Fifth of D-dimer } \\
\hline & & 1 & 2 & 3 & 4 & 5 & Total \\
\hline \multirow{6}{*}{$\begin{array}{l}\text { Fifth of } \\
\text { D-dimer } \\
\text { Gold }\end{array}$} & 1 & $141(7 \%)$ & $107(6 \%)$ & $52(3 \%)$ & $45(2 \%)$ & $11(1 \%)$ & 356 \\
\hline & 2 & $136(7 \%)$ & $112(6 \%)$ & $107(6 \%)$ & $56(3 \%)$ & $32(2 \%)$ & 443 \\
\hline & 3 & $72(4 \%)$ & $88(5 \%)$ & $95(5 \%)$ & $97(5 \%)$ & $44(2 \%)$ & 396 \\
\hline & 4 & $36(2 \%)$ & $60(3 \%)$ & $90(5 \%)$ & $105(5 \%)$ & $86(4 \%)$ & 377 \\
\hline & 5 & $16(1 \%)$ & $20(1 \%)$ & $33(2 \%)$ & $81(4 \%)$ & $223(11 \%)$ & 373 \\
\hline & Total & 401 & 387 & 377 & 384 & 396 & 1945 \\
\hline
\end{tabular}




\begin{tabular}{|lllllll|}
\hline & \multicolumn{5}{c}{ Fifth of D-dimer } \\
\hline D-dimer original & $\mathbf{1}$ & $\mathbf{2}$ & $\mathbf{3}$ & $\mathbf{4}$ & $\mathbf{5}$ & Total \\
$\quad$ Range in ng/ml & $\leq 46$ & $47-61$ & $62-78$ & $79-106$ & $\geq 107$ & \\
$\quad$ Number of men & 407 & 397 & 393 & 396 & 405 & 1998 \\
Number (\%) with Incident IHD & $13(3.2 \%)$ & $24(6.0 \%)$ & $16(4.1 \%)$ & $29(7.3 \%)$ & $47(11.6 \%)$ & $129(6.5 \%)$ \\
Relative odds of IHD & 1.0 & 1.91 & 1.25 & 2.26 & 3.68 & \\
& & & & & & \\
D-dimer Gold & & & & & & \\
$\quad$ Range in ng/ml & & & & & & \\
Number of men & 357 & 443 & 397 & 377 & 373 & 1947 \\
Number (\%) with Incident IHD & $11(3.1 \%)$ & $19(4.3 \%)$ & $25(6.3 \%)$ & $26(6.9 \%)$ & $46(12.3 \%)$ & $127(6.5 \%)$ \\
Relative odds of IHD & 1.0 & 1.38 & 2.03 & 2.23 & 4.10 & \\
\hline
\end{tabular}

Table 2 Incidence and age-related relative odds of IHD over 5 years by fifths of D-dimer and D-dimer gold

\begin{tabular}{|c|c|c|c|c|c|c|c|c|}
\hline & $\begin{array}{l}\text { D-dimer } \\
\text { (original) }\end{array}$ & $\begin{array}{l}\text { D-dimer } \\
\text { (Gold) }\end{array}$ & Fibrinogen & $\begin{array}{l}\text { Factor } \\
\text { VIIIc }\end{array}$ & $\begin{array}{l}\text { Fragment } \\
1+2\end{array}$ & TAT & $\begin{array}{l}\text { Factor } \\
\text { VIIc }\end{array}$ & APTT \\
\hline D-dimer (Gold) & $0.59^{* *}$ & & & & & & & \\
\hline Fibrinogen & $0.36^{* *}$ & $0.30 * *$ & & & & & & \\
\hline Factor VIIIlc & $0.16^{* *}$ & $0.20 * *$ & $0.20 * *$ & & & & & \\
\hline Fragment $1+2$ & $0.31 * *$ & $0.25^{* *}$ & 0.01 & $0.07 *$ & & & & \\
\hline TAT & $0.12^{* *}$ & $0.12 * *$ & 0.07 & 0.05 & $0.36^{* *}$ & & & \\
\hline Factor VIIc & 0.01 & 0.01 & 0.03 & $0.09^{* *}$ & $0.12 * *$ & 0.05 & & \\
\hline APTT & 0.01 & -0.03 & $0.11^{* *}$ & $-0.57^{* *}$ & $-0.13^{* *}$ & -0.07 & $-0.09 *$ & \\
\hline APC ratio & $-0.15 * *$ & $-0.11^{* *}$ & -0.00 & $-0.24 * *$ & $-0.17 * *$ & $-0.09 *$ & $-0.16^{* *}$ & $0.19^{* *}$ \\
\hline
\end{tabular}

\begin{tabular}{|c|c|c|c|c|c|}
\hline & $\mathbf{N}$ & $\begin{array}{l}\frac{\text { No IHD }}{\text { Mean (IQR) }} \\
\text { (IQR }\end{array}$ & $\mathbf{N}$ & $\begin{array}{l}\underline{\text { IHD }} \\
\text { Mean (IQR) }\end{array}$ & $\begin{array}{l}\text { Age-adjusted mean difference } \\
(95 \% \text { confidence interval); } p \text { value }\end{array}$ \\
\hline $\begin{array}{l}\text { D-dimer original } \\
(\mathrm{ng} / \mathrm{ml})\end{array}$ & 1869 & $70.7(49-95)$ & 129 & $89.6(58-125)$ & $0.21(0.11$ to 0.30$) ; \mathrm{p}<0.0001$ \\
\hline $\begin{array}{l}\text { D-dimer Gold } \\
(\mathrm{ng} / \mathrm{ml})\end{array}$ & 1820 & $11.3(7-20)$ & 127 & $18.6(11-37)$ & 0.45 ( 0.27 to 0.63$) ; \mathrm{p}<0.0001$ \\
\hline $\begin{array}{l}\text { Fragment } 1+2 \\
(\mathrm{nmol} / \mathrm{L})\end{array}$ & 1273 & $1.40(1.10-1.73)$ & 87 & $1.46(1.16-1.75)$ & $0.039(-0.055$ to 0.134$) ; \mathrm{p}=0.42$ \\
\hline $\mathrm{TAT}(\mu \mathrm{g} / \mathrm{L})$ & 1155 & $7.44(4.8-11.3)$ & 78 & $7.56(4.9-10.8)$ & $0.015(-0.122$ to 0.152$) ; \mathrm{p}=0.83$ \\
\hline Factor VIIc (iu/dl) & 1322 & $110.7(98-124)$ & 90 & $108.4(93-121)$ & $-2.15(-6.80$ to 2.51$) ; p=0.37$ \\
\hline APTT (sec) & 1273 & $33.0(31.2-34.7)$ & 81 & $32.8(31.0-34.3)$ & $-0.006(-0.027$ to 0.015$) ; p=0.60$ \\
\hline APC ratio & 1247 & $3.29(3.01-3.58)$ & 78 & $3.20(2.89-3.53)$ & $-0.087(-0.205$ to 0.032$) ; p=0.15$ \\
\hline
\end{tabular}

Table 3 Correlation coefficients between D-dimer assays, fibrinogen, factor VIIIc and coagulation activation markers

Table 4 Mean levels (with inter-quartile range, IQR) and age-adjusted mean differences (with 95\% confidence intervals) between men who developed major IHD over 5 years and those who did not 
Table 5 Incidence, age, adjusted relative odds of IHD over 5 years, and t-tests for trends by fifths of coagulation activtion markers

\begin{tabular}{|c|c|c|c|c|c|c|c|}
\hline Fragment $1+2$ & 1 & 2 & 3 & 4 & 5 & Total & $P$ for trend \\
\hline Incidence & $\begin{array}{l}14 / 266 \\
(5.3 \%)\end{array}$ & $\begin{array}{l}14 / 277 \\
(5.0 \%)\end{array}$ & $\begin{array}{l}19 / 271 \\
(7.0 \%)\end{array}$ & $\begin{array}{l}22 / 274 \\
(8.0 \%)\end{array}$ & $\begin{array}{l}18 / 272 \\
(6.6 \%)\end{array}$ & $\begin{array}{l}87 / 1360 \\
(6.4 \%)\end{array}$ & 0.41 \\
\hline Relative odds & 1.0 & 0.94 & 1.31 & 1.51 & 1.21 & & \\
\hline \multicolumn{8}{|l|}{ TAT } \\
\hline Incidence & $\begin{array}{l}15 / 244 \\
(6.1 \%)\end{array}$ & $\begin{array}{l}16 / 249 \\
(6.4 \%)\end{array}$ & $\begin{array}{l}15 / 245 \\
(6.1 \%)\end{array}$ & $\begin{array}{l}19 / 249 \\
(7.6 \%)\end{array}$ & $\begin{array}{l}13 / 246 \\
(5.3 \%)\end{array}$ & $\begin{array}{l}78 / 1233 \\
(6.3 \%)\end{array}$ & 0.83 \\
\hline Relative odds & 1.0 & 1.04 & 1.00 & 1.25 & 0.84 & & \\
\hline \multicolumn{8}{|l|}{ Factor VIIc } \\
\hline Incidence & $\begin{array}{l}26 / 295 \\
(8.8 \%)\end{array}$ & $\begin{array}{l}20 / 289 \\
(6.9 \%)\end{array}$ & $\begin{array}{l}15 / 267 \\
(5.6 \%)\end{array}$ & $\begin{array}{l}13 / 278 \\
(4.7 \%)\end{array}$ & $\begin{array}{l}16 / 283 \\
(5.7 \%)\end{array}$ & $\begin{array}{l}90 / 1412 \\
(6.4 \%)\end{array}$ & 0.36 \\
\hline Relative odds & 1.0 & 0.76 & 0.60 & 0.51 & 0.63 & & \\
\hline \multicolumn{8}{|l|}{ APTT } \\
\hline Incidence & $\begin{array}{l}20 / 277 \\
(7.2 \%)\end{array}$ & $\begin{array}{l}14 / 298 \\
(4.7 \%)\end{array}$ & $\begin{array}{l}13 / 258 \\
(5.0 \%)\end{array}$ & $\begin{array}{l}20 / 268 \\
(7.5 \%)\end{array}$ & $\begin{array}{l}14 / 253 \\
(5.5 \%)\end{array}$ & $\begin{array}{l}81 / 1354 \\
(6.0 \%)\end{array}$ & 0.60 \\
\hline Relative odds & 1.0 & 0.63 & 0.66 & 1.02 & 0.76 & & \\
\hline \multicolumn{8}{|l|}{ APC ratio } \\
\hline Incidence & $\begin{array}{l}20 / 268 \\
(7.5 \%)\end{array}$ & $\begin{array}{l}21 / 259 \\
(8.1 \%)\end{array}$ & $\begin{array}{l}13 / 267 \\
(4.9 \%)\end{array}$ & $\begin{array}{l}9 / 264 \\
(3.4 \%)\end{array}$ & $\begin{array}{l}15 / 267 \\
(5.6 \%)\end{array}$ & $\begin{array}{l}78 / 1325 \\
(5.9 \%)\end{array}$ & 0.15 \\
\hline Relative odds & 1.0 & 1.09 & 0.64 & 0.45 & 0.77 & & \\
\hline
\end{tabular}

Table 3 shows that each assay for D-dimer correlated significantly with plasma fibrinogen, FVIIIc, F1+2, TAT, and APC ratio (the latter correlation being inverse); but not with APTT or FVIIc. The strength and pattern of all these correlations was very similar for the two D-dimer assays. There were also significant correlations between the other activation markers, notably FVIIIc and APTT.

Tables 4 and 5 shows that, in contrast to D-dimer, fibrinogen (16) and FVIIIc (17), no significant associations with incident IHD were observed for F1+2, TAT, FVIIc, APTT or APC ratio.

\section{Disc ussion}

The first aim of this study was to establish whether, in view of the heterogeneity of D-dimer and its assays (9), the association of plasma D-dimer with incident IHD which we have previously reported in the Caerphilly Study cohort (3) could be validated using a more specific assay for D-dimer which employs a more specific signal antibody (10). In agreement with a previous comparison (10), we observed a strong correlation between these two assays. As expected, the more specific assay gave lower values for plasma D-dimer than the original assay (10); and there was also some variation between distributions by fifths (Table 1). Nevertheless, the main finding of this comparison was that the more specific assay showed an association with incident IHD which was at least as strong, and as independent of other risk factors including fibrinogen, as that which we reported (3) for the original assay (Table 2 ). We therefore conclude that a significant association exists between the various plasma fibrin derivatives which contain D-dimer (9) and incident IHD. These findings in the present study are consistent with those of other prospective studies of cardiovascular events, in cohorts both with and without evidence of baseline cardiovascular disease (4). Recently, comparison of two different D-dimer assays showed that they had similar associations with recurrent thrombotic events following myocardial infarction $(18,19)$. Together with the results of the present study, these data support the consistency of the association of plasma D-dimer with incident IHD, regardless of assay type. However, further comparative studies are required.

We have suggested that increased plasma D-dimer levels in persons developing IHD might reflect increased activation of blood coagula- tion, because similar elevations of coagulation activation markers and D-dimer have been observed in patients with chronic arterial disease (4-6), and because increased plasma D-dimer levels can be normalised by anticoagulation with warfarin $(7,8)$. However, we are unaware of reported studies of the correlations between D-dimer and markers of activated coagulation in large samples of the general population. Therefore, the second aim of this study was to examine the correlations of both D-dimer assays with several markers of activated coagulation; and also to examine the associations of these markers with incident IHD.

Both D-dimer assays correlated similarly with plasma fibrinogen $(r=0.30-0.36$; Table 3), which has been associated with incident IHD in this cohort (16). These correlations might arise from mutual correlations with age, smoking and baseline arterial disease (20); from an influence of fibrinogen on D-dimer formation; or vice versa (e.g. from stimulation of hepatic fibrinogen synthesis by fibrin(ogen) degradation products including D-dimer) (4). However, inclusion of fibrinogen in multivariate analyses had virtually no effect on the associations of either type of D-dimer assay with IHD, hence such associations do not appear to result from the influence of fibrinogen levels.

Both D-dimer assays also correlated with factor VIIIc, which has also been associated with incident IHD in this cohort (17). As with fibrinogen, these correlations might arise from mutual correlations with age (21); from an influence of factor VIIIc on thrombin and fibrin formation, and hence D-dimer formation; or from a mutual influence of thrombin formation on activation of FVIII and on D-dimer formation. However, this association was weak $(r=0.16-0.20)$.

The coagulation activation markers, F1+2 and (to a lesser extent) TAT, also showed significant correlations with both D-dimer assays. These correlations, which have been observed in other studies (22), might arise from mutual correlations with age, risk factors, or baseline arterial disease $(11,12,21)$; or from an influence of thrombin formation (leading to F1+2 and TAT formation) on formation of fibrin and hence on D-dimer. However, these activation markers were not associated with incident IHD in this cohort, hence they do not appear to explain the association of D-dimer assays with incident IHD

Activated protein $\mathrm{C}$ resistance (as measured by a low APC ratio) also correlated with both D-dimer assays, as well as F1+2 and TAT. These associations, which have been observed in other studies $(15,22)$ 
might reflect effects of increased VIIIc levels on both coagulation activation (21) and on APC resistance $(15,21)$; or else that a low APC ratio is associated with a hypercoagulable state (15). However, APC ratio was not associated with incident IHD in this study cohort, nor with prevalent IHD in other studies $(15,23)$, hence again this assay does not explain the association of D-dimer assays with incident IHD. APTT, while associated with coagulation activation and incident DVT in other studies (22), was associated with neither D-dimer assays nor with incident IHD in the present study.

We observed no correlation of FVIIc with D-dimer assays, although several studies have correlated FVII assays with coagulation activation markers such as fibrinopeptide A, F1+2 and TAT $(12,21)$. This negative finding may reflect the limited range of FVIIc in the present study, because in contrast anticoagulation with warfarin (which lowers FVIIc) has been shown to normalise elevated D-dimer levels in several studies $(7,8,24)$. We also observed no independent association of FVIIc with incident IHD in this cohort, as have several other prospective studies (25-27). The association of FVIIc with incident IHD in the first Northwick Park Heart Study (13) may reflect a higher sensitivity of the FVIIc assay used in that study to FVIIa (28).

There are several limitations of the current study. First, activation markers could only be assayed in the two-thirds of the sample for which an unthawed plasma sample was available. We have compared this subsample with the total sample, and confirmed that no selection bias occurred. We also examined the association of D-dimer with IHD in the subsample in whom activation markers were measured, and confirmed that both D-dimer assays were significantly associated with IHD within this subsample. Second, the short half-lives (min) of activation markers in the circulation make it more difficult to establish an association with incident IHD, compared to D-dimer which has a longer half-life (h). For both these reasons, further, larger studies are required to study the associations of activation markers with IHD. Third, the current study included only men: a recent report (29) suggested the possibility that D-dimer was not of prognostic value in women compared to men (although only 14 events occurred in women in this study). Hence, further studies of the association of D-dimer with incident IHD in women are required.

In conclusion, the present study confirms with a specific assay a strong association of fibrin D-dimer with incident IHD, but does not clearly establish a role for several assays of coagulation activation or thrombotic tendency in explaining this association (perhaps due to a lower study power). We suggest that further studies are required to investigate other potential causes of this association. These may include an effect of disturbed blood flow (e.g. due to atherosclerotic plaques) on D-dimer, as seen in patients with atrial fibrillation undergoing cardioversion (30); and the possible association of fibrin turnover with the inflammatory component of atherosclerosis (31).

\section{Acknowledgements}

We thank the British Heart Foundation for financial support, and Ann Harold and Ruth Simpson for typing the manuscript.

\section{References}

1. Gaffney PJ, Brasher M. Subunit structure of the plasmin-induced degradation products of cross-linked fibrin. Biochem Biophys Acta 1973; 295: 308-13.

2. Lip GYH, Lowe GDO. Fibrin D-dimer: a useful clinical marker of thrombogenesis? Clin Sci 1995; 89: 205-14.
3. Lowe GDO, Yarnell JWG, Sweetnam PM, Rumley A, Thomas HF, Elwood PC. Fibrin D-dimer, tissue plasminogen activator, plasminogen activator inhibitor, and the risk of major ischaemic heart disease in the Caerphilly Study. Thromb Haemost 1998; 79: 129-33.

4. Lowe GDO, Rumley A. Use of fibrinogen and fibrin in prediction of arterial thrombotic events. Thromb Haemost 1999; 82: 667-72.

5. Al-Zahrani H, Lowe GDO, Douglas JT, Cuschieri R, Pollock JG, Smith WCS. Increased fibrin turnover in peripheral arterial disease: comparison with a population study. Clin Hemorheol 1992; 12: 867-72.

6. Lee AJ, Fowkes FGR, Lowe GDO, Rumley A. Fibrin D-dimer, haemostatic factors and peripheral arterial disease. Thromb Haemost 1995; 74: $828-32$.

7. Lip GYH, Lowe GDO, Rumley A, Dunn FG. Increased markers of thrombogenesis in chronic atrial fibrillation: effects of warfarin treatment. Br Heart J 1995; 73: 527-33.

8. Lip GYH, Zafiris J, Watson RDS, Bareford D, Lowe GDO, Beevers DG. Fibrin D-dimer and beta-thromboglobulin as markers of thrombogenesis and platelet activation in atrial fibrillation. Effects of introducing ultralow-dose warfarin and aspirin. Circulation 1996; 94: 425-31.

9. Gaffney PJ, Edgell T, Creighton-Kempsford LJ, Wheeler S, Tarelli E. Fibrin degradation product (FnDP) assays: analysis of standardization issues and target antigens in plasma. Br J Haematol 1995; 90: 187-94.

10. Hart R, Bate I, Dinh D, Elms M, Bundesen P, Hillyard C, Rylatt DB. The detection of D-dimer in plasma by enzyme immunoassay: improved discrimination is obtained with a more specific signal antibody. Blood Coagul Fibrinolys 1994; 5: 227-32.

11. Mannucci PM. Mechanisms, markers and management of coagulation activation. Br Med Bull 1994;50: 857-70

12. Miller GJ, Bauer KA, Barzegar S, Cooper JA, Rosenberg RD. Increased activation of the haemostatic system in men at high risk of fatal coronary heart disease. Thromb Haemost 1996; 75: 767-71

13. Meade TW, Mellows S, Brozovic M, Miller GJ, Chakrabarti RR, North WRS, Haines AP, Stirling Y, Imeson JD, Thompson SG. Haemostatic function and ischaemic heart disease: principal results of the Northwick Park Heart Study. Lancet 1986; ii: 533-7.

14. Dahlback B, Carlsson M, Svensson PJ. Familial thrombophilia due to a previously unrecognized mechanism characterized by poor anticoagulant response to activated protein $\mathrm{C}$ : prediction of a cofactor to activated protein C. Proc Nat Acad Sci 1993; 90: 1004-8.

15. Lowe GDO, Rumley A, Woodward M, Reid E, Rumley J. Activated protein $\mathrm{C}$ resistance and the FV: R506Q mutation in a random population sample: associations with cardiovascular risk factors and coagulation variables. Thromb Haemost 1999; 81: 918-24.

16. Sweetnam PM, Yarnell JWG, Lowe GDO, Baker IA, O’Brien JR, Rumley A, Etherington MD, Whitehead PJ, Elwood PC. The relative power of heat-precipitation nephelometric and clottable (Clauss) fibrinogen in the prediction of ischaemic heart disease: the Caerphilly and Speedwell studies. Br J Haematol 1998, 100, 582-8.

17. Rumley A, Lowe GDO, Sweetnam PM, Yarnell JWG, Ford RP. Factor VIII, von Willebrand factor and the risk of major ischaemic heart disease in the Caerphilly Study. Br J Haematol 1999; 105: 110-6.

18. Moss AJ, Goldstein RE, Marder VJ, Sparks CE, Oakes D, Greenberg H, et al. Thrombogenic factors and recurrent coronary events. Circulation 1999; 99: 2517-22.

19. Marder VJ, Zareba W, Horan JT, Moss AJ, Kanouse JJ. Automated latex agglutination and ELISA testing yield equivalent D-dimer results in patients with recent myocardial infarction. Thromb Haemost 1999; 82: 1412-6.

20. Yarnell JWG, Sweetnam PM, Rumley A, Lowe GDO. Lifestyle and hemostatic risk factors for ischaemic heart disease. The Caerphilly Study. Arterioscler Thromb Vasc Biol 2000; 20: 271-79.

21. Lowe GDO, Rumley A, Woodward M, Morrison CE, Philippou H, Lane DA, Tunstall-Pedoe H. Epidemiology of coagulation factors, inhibitors and activation markers: The Third Glasgow MONICA Survey. I. Illustrative reference ranges by age, sex and hormone use. Br J Haematol, 1997; 97 : $775-84$. 
22. Lowe GDO, Haverkate F, Thompson SG, Turner RM, Bertina RM, Turpie AGG, Mannucci, PM, on behalf of the ECAT DVT Study Group. Prediction of deep vein thrombosis after elective hip replacement surgery by preoperative clinical and haemostatic variables: the ECAT DVT Study. Thromb Haemost 1999;81: 879-86.

23. van der Bom JG, Bots ML, Haverkate F, Slagboom PE, Meijer P, de Jong TVM, Hofman A, Grobbee DE, Kluft C. Reduced response to activated protein $\mathrm{C}$ is associated with increased risk for cerebrovascular disease. Ann Intern Med 1996; 125: 265-9.

24. Eritsland J, Seljeflot I, Arnesen H, Smith P, Westvik AB. Effects of long-term treatment with warfarin on fibrinogen, FpA, TAT, and D-dimer in patients with coronary artery disease. Thromb Res 1992; 66: 55-60.

25. Junker R, Heinrich J, Schulte H, van de Loo J, Assmann G. Coagulation factor VII and the risk of coronary heart disease in healthy men. Arterioscler Thromb Vasc Biol 1997; 17: 1539-44.

26. Folsom AR, Wu KK, Rosamond WD, Sharrett AR, Chambless LE. Prospective study of hemostatic factors and incidence of coronary heart disease: the Atherosclerosis Risk in Communities (ARIC) Study. Circulation 1997; 96: 1102-8.

27. Smith FB, Lee AJ, Fowkes FGR, Price JF, Rumley A, Lowe GDO. Haemostatic factors as predictors of ischaemic heart disease and stroke in the Edinburgh Artery Study. Arterioscler Thromb Vasc Biol 1997; 17: 3321-5.

28. Miller GJ, Stirling Y, Esnouf MP, Heinrich J, van de Loo J, Kienast J, et al. Factor VII-deficient substrate plasmas depleted of protein $\mathrm{C}$ raise the sensitivity of the factor VII bio-assay to activated factor VII: an international study. Thromb Haemost 1994; 71: 38-48.

29. Kalaria VG, Zareba W, Moss AJ, Pancio G, Marder VJ, Morrissey JH, Weiss HJ, Sparks CE, Greenberg H, Dwyer E, Goldstein R, Watelet LFM. Gender-related differences in thrombogenic factors predicting recurrent cardiac events in patients after acute myocardial infarction. Am J Cardiol 2000; 85: 1401-8.

30. Lip GYH, Rumley A, Dunn FG, Lowe GDO. Plasma fibrinogen and fibrin D-dimer in patients with atrial fibrillation: effects of cardioversion to sinus rhythm. Int J Cardiol 1995; 51: 245-51.

31. Lowe GDO, Yarnell JWG, Rumley A, Bainton D, Sweetnam PM. C-Reactive protein, fibrin D-dimer and incident ischaemic heart disease in the Speedwell Study. Are inflammation and fibrin turnover linked in pathogenesis? Arterioscler Thromb Vasc Biol 2001; 21: 603-10.

Received June 26, 2000 Accepted after resubmission April 3, 2001 